Thélème. Revista Complutense de Estudios Franceses ISSN-e: 1989-8193

http://dx.doi.org/10.5209/THEL.60018

\title{
Extranjeros por herencia: Isabelle Alonso en busca de una identidad
}

\author{
Rita Rodríguez Varela ${ }^{1}$
}

Recibido: 19/04/2018 / Aceptado: 08/10/2018

Resumen. El acercamiento a la literatura francesa escrita por exiliados de origen español, tiende a obviar las diferencias existentes entre los miembros de las primeras y segundas generaciones. Debido a la amplia presencia de escritores con este perfil en el corpus literario francés, cabe profundizar en el entendimiento de sus especificidades.

Este estudio tiene como objetivo ahondar en las características de la segunda generación a través de la obra de Isabelle Alonso, especialmente en su novela L'Exil est mon pays (2006). Para ello, se estudiará la relación de la protagonista con su familia para destacar las diferencias así como su repercusión en su formación identitaria, se analizará el imaginario colectivo francés sobre los españoles y se expondrán las consecuencias de la dualidad lingüística.

Palabras clave: exilio; identidad; bilingüismo; multiculturalidad; estereotipos.

\section{[fr] Étrangers d'héritage: Isabelle Alonso à la recherche d'une identité}

Résumé. Le rapprochement à la littérature française écrite par des exilés d'origine espagnole, a tendance à oublier les différences existantes entre les membres des premières et deuxièmes générations. Du fait de l'ample présence d'écrivains avec ce profil dans le corpus littéraire français, il convient d'approfondir la compréhension de leurs spécificités.

Cette étude a pour objectif d'analyser plus à fond les caractéristiques de la deuxième génération à travers l'oeuvre d'Isabelle Alonso, concrètement dans son roman L'Exil est mon pays (2006). Pour cela, on étudiera la relation de la protagoniste avec sa famille pour détacher les différences ainsi que les répercussions sur sa formation identitaire ; on analysera l'imaginaire collectif français sur les Espagnols et on exposera les conséquences de la dualité linguistique.

Mots clés: exil, identité, bilinguisme, multiculturalité, stéréotypes.

\section{[en] Foreigners for heritage: Isabelle Alonso in search of an identity}

\begin{abstract}
The study of the French literature written by Spanish exiles sometimes forgets the differences between the members of the first and the second generations of exiles. It's important to deepen into the comprehension of their specificities and the differences because of the wide presence of writers with this profile in the literary corpus.

This study aims to study the characteristics of the second generation of exiles across Isabelle Alonso works, specially in her novel L'Exil est mon pays (2006). This article will be studied the relation of the protagonist by her family to emphasize the differences and the repercussion in her identity, will be analyzed the imaginary French group about the Spanish and there will be exposed the consequences of the linguistic duality.
\end{abstract}

Keywords: exile; identity; bilingualism; multiculturalism; stereotypes.

$1 \quad$ rirova@alumni.uv.es

Universidad de Valencia 
Sumario. Introducción. La familia. La herencia del tópico. Vivir entre dos lenguas. Conclusión.

Cómo citar: Rodríguez Varela, R. (2019). "Extranjeros por herencia: Isabelle Alonso en busca de una identidad". Thélème. Revista Complutense de Estudios Franceses. Vol. 34, Núm. 1: 227-243.

\section{Introducción}

En las últimas décadas, los estudios sociológicos apuntan a un cambio crucial identitario en las sociedades, a causa de los conflictos históricos que promueven el desplazamiento masivo de la población y a los cambios relacionales entre las sociedades producto de la creciente globalización. La principal consecuencia de esta traslación social es el avance de los elementos tradicionalmente conflictuales hacia un concepto de la identidad como un componente ecléctico, multicultural, híbrido, es decir, como un elemento que se encuentra en continuo cambio e intercambio.

En esta búsqueda de una adecuación identitaria y de la necesidad de encontrar y situarse un espacio definitorio y seguro, ante un historial vital caracterizado por la hibridación, se encuentran las obras de los escritores de la segunda generación de exiliados. Si bien existen amplios estudios críticos que analizan los testimonios literarios sobre la guerra civil española y el exilio escritos por autores de la primera generación, lo cierto es que todavía no se ha profundizado suficientemente en el estudio de las especificidades y de las diferencias de los hijos de esos exiliados, es decir, de la mal denominada segunda generación. Esta denominación es errónea puesto que da a entender que se trata de una réplica de la generación anterior, como si se tratara de una segunda remesa de extranjeros, cuando, en realidad, se trata de ciudadanos que han nacido en el país de acogida y, por tanto, existen grandes diferencias entre ambas generaciones.

En esta línea, la obra de Isabelle Alonso L'Exil est mon pays (2006) ofrece un punto de vista muy enriquecedor para el corpus literario francófono con raíces españolas pues permite reflexionar sobre el concepto de extranjería como un elemento hereditario. El tema principal de la obra es la dificultad de conservar la identidad frente a un mundo que se presenta hostil ante las diferencias. Los personajes comparten una relación con la comunidad y con el lenguaje basada en la alteridad por lo que deben luchar para conseguir preservar su autenticidad y peculiaridad.

Este artículo analizará la novela, en primer lugar, desde un punto de vista familiar, puesto que los miembros de la familia Alcalá ocupan un lugar central y tienen una gran repercusión en la vida de la protagonista. Se determinará cuál es el papel que cumple cada personaje en el camino del exilio, así como el valor que aportan en la formación identitaria de Angustias, la protagonista. En segundo lugar, se analizará el imaginario colectivo presente en la sociedad francesa pues, siendo la protagonista una "extranjera por herencia", dichas imágenes tienen consecuencias no solo en sus padres sino también en ella. En último lugar, se estudiará el factor lingüístico para entender cómo la existencia de dos lenguas provoca la existencia de dos espacios donde se sitúan diferentes parcelas y facetas de su vida. En este marco, se verá cómo la protagonista debe luchar para encontrar una manera de inscribirse en un territorio que se caracteriza por la dualidad y la inestabilidad. La lengua no solo es un medio 
de comunicación sino también un elemento definitorio de la identidad con unas consecuencias decisivas en el sujeto.

\section{La familia}

La pertenencia a una familia, una comunidad o una tribu son algunos de los elementos sobre los que se forma y se afianza la identidad de los sujetos. El ser humano nace y desarrolla sus primeras etapas de vida en familia y, por este motivo, ésta deja una marca característica en el desarrollo de su identidad. Las primeras enseñanzas, valores y creencias, nacen en el hogar, rodeado de los miembros del núcleo familiar $y$, en este sentido, se afirma que:

La familia está íntimamente vinculada a la ontogénesis de cada ser humano y acompaña una parte fundamental de su desarrollo, especialmente en el momento de formación de la identidad personal. En ella se aprende qué significa ser persona (Morandé, 1998: 9-10).

Desde el campo de la sociología, la familia figura como un ámbito intermedio que funciona como mediadora entre el individuo y la sociedad. La manera en que el hombre conoce y piensa el mundo es, en gran parte, producto de la familia en la que crece al igual que forja lo que para él significa ser persona. En esta línea, Morandé (1998) afirma que es la célula básica de la sociedad. Este autor pone de relieve igualmente el papel del núcleo familiar como transmisor de la cultura y de la memoria histórica. Esto se debe a que al situarse como el elemento más cercano al origen ontogenético del individuo y al otorgarle el sentimiento de pertenencia "ella misma es quien le interroga acerca del significado de la tradición cultural heredada de las generaciones precedentes" (1998: 42). Entre las formas de aprendizaje cultural, figuran el diálogo cotidiano y la convivencia entre los miembros, así como la evaluación crítica de dicha experiencia, éstas a su vez formarán a un sujeto crítico y concienzudo en lo que se refiere al respeto y a la valoración tanto personal como colectiva.

La obra de análisis de este estudio, L'Exil est mon pays, es una novela familiar a causa del decisivo papel que cumple y de la intensa profundización realizada por la autora, con lo cual, resulta imprescindible comenzar analizando la función que ejerce cada uno de los miembros de la familia Alcalá en la vida de Angustias, la protagonista. Se hará un retrato de los personajes para observar qué valor aportan a la formación identitaria de la protagonista, así como para exponer las diferencias existentes entre ambas generaciones de extranjeros.

El universo novelesco de Isabelle Alonso está marcado por la cercana y tierna relación de Angustias y su familia, los Alcalá, compuesta por Libertad y Ángel, los padres, y sus cuatro hijos: Gonzalo, Rodrigo, Remedios y Angustias.

La historia del exilio de esta familia se sitúa en la frontera. En el caso del padre, es consciente de que esta acción no tiene vuelta atrás pues, a causa de sus actividades políticas en España, está obligado a buscar una falsa identidad y a vivir en la clandestinidad. De igual forma, Libertad, pasa la frontera seis meses después de su marido, pero bajo la condición de madre soltera pues "dans la très catholique Espag- 
ne franquiste, fille-mère, état scabreux s'il en fût, est mille fois préférable à épousede-rouge" (Alonso, 2006: 13).

Superadas las dificultades para abandonar España, los Alcalá se instalan en Vieillottes, una pequeña ciudad húmeda, cerca de Auxerre, donde empiezan una nueva vida, lejos de la dictadura franquista.

La figura paterna cumple el papel de representante de la conciencia de clase y es el portador de la escritura y la lectura, así señala la protagonista que "il est à la lecture du journal ce que l'homme-orchestre est à la musique" (Alonso, 2006: 125). Mientras que sus compañeros de clase tienen padres a los que les gusta el bricolaje o la bebida, el suyo se singulariza por su pasión por la lectura:

Il lisait le matin en sirotant le café quasi solide qui lui permettait de ne pas s'endormir sur sa machine. Il lisait à midi, à l'atelier, en avalant distraitement sa gamelle pendant que les autres parlaient cul ou tiercé. Il continuait pendant le dîner, à haute voix pour que maman en profite. Il ne se laissait pas de savourer, jour après jour, les joies de la liberté de la presse (Alonso, 2006: 67).

En la novela dedicada enteramente a la figura paterna, Je mourrais une autre fois (2016), describe al padre como un niño con una gran inquietud intelectual, deseoso de aprender, de leer todo aquello que cae en sus manos: “je suis pris d'une frénésie de lecture, tout ce qui me tombe sous la main, Fenimore Cooper, Molière, Valle-Inclán, Alexander Dumas et même Alberto Insúa, un écrivain cubain pas du tout pour les enfants" (Alonso, 2016: 101). El poder y la magia de las palabras le apasionan y mientras otros niños se sienten atraídos por los juegos, él prefiere coleccionar palabras, complicadas o extrañas. La protagonista hereda este amor por la lectura y es descrita disfrutando de Don Quijote, Platero y yo, los Tres Mosqueteros, Veinte mil leguas de viaje submarino, entre otras obras. Como explica Morandé, la vida humana se experimenta en su temporalidad, puesto que el individuo proyecta sus expectativas de futuro, "de cumplimiento de una posibilidad de ser (1998: 43) y de realización personal en la familia. Dichas expectativas se dirigirán a un camino o a otro según los cimientos sobre los que se asienta. En el caso de Angustias, es indiscutible que la figura paterna tiene una repercusión muy acusada en la formación de su conciencia crítica de la realidad y de los sucesos de la historia, así como de su pasión por la lectura.

Si el padre es la figura protectora del país de origen, de unos ideales de justicia y de igualdad sociales y el transmisor de la literatura, la madre aparece representada como la gran protectora del hogar y de la familia. La protagonista muestra un amor y una admiración total hacia su madre, a la que describe como una mujer valiente, indomable y generosa:

J'idolâtrais ma mère. Libertad. Maman merveille, maman trésor, si belle, si habile. Si princesse à mes yeux qu'elle n'avait pas besoin des accessoires. Pas de tiare, pas de ceinture dorée, pas de robe brillante. La perfection sans artifice. Je la suivais partout. Je passais des heures à la contempler (Alonso, 2006: 55).

Posee todas las cualidades que una madre debe tener para hacer funcionar una familia con pocos recursos: organiza la casa, sabe negociar, no permite que a sus 
hijos les falte de nada, ni psíquica ni físicamente. Es presentada con una gran fortaleza, como una mujer que ha vivido rodeada de las sirenas y de los bombardeos de la guerra y ahora se siente afortunada de poder empezar una nueva vida. Libertad ha perdido lo que Tzvetan Todorov bautizó como "la peur d'avoir peur" (1989: 8), presente en muchas víctimas de guerra. En este sentido, cuando la autora enumera todo lo que le ha sido arrebatado a su familia: la patria, la lengua, los amigos o las costumbres, adjunta también la pérdida del miedo:

Peur des flics, de curés, de militaires, de ceux qui détiennent le pouvoir de ruiner votre vie pour un regard, pour une parole. Peur de se trahir, de dire le mauvais mot au mauvais moment, peur des mouchards, de l'arrestation, des coups, de la prison, des risques qu'on fait prendre à ceux qu'on aime. Peur familière, apprivoisée, partagée. Peur générale (Alonso, 2006: 19).

A pesar de ello, la vida en Francia no es presentada idílicamente, sino que, en cierta medida, se produce un cambio de miedo pues si antes era rica en un país pobre, ahora es pobre en un país rico. Sin embargo, como se señalaba anteriormente, Alonso muestra un personaje que rechaza el papel de víctima y que suple las carencias gracias a su audacia e ingenio: "la pauvreté, c'est tout un art. Un funambulisme permanent qui ne laisse aucune place au hasard et n'admet pas l'imprévu" (Alonso, 2006: 48). Todas estas peripecias realizadas por la madre, junto con las características ya descritas del padre, dictan e influencian las pautas de conducta de su hija, la cual protagoniza diversas hazañas en el colegio en defensa del más débil y de unos valores de justicia. El asentamiento de aquello que debe ser considerado como justo y razonable, es decir, de las pautas de valor del sujeto comienzan a desarrollarse en el núcleo familiar, en un cuádruple proceso de mímesis, es decir, imitación de los miembros del círculo cercano, de orientaciones cognitivas, éticas y estéticas. Por lo tanto, la capacidad de diferenciar el bien del mal o la belleza de la fealdad, crece y prospera a raíz de las actuaciones y enseñanzas de los padres. Asimismo, "la historicidad y mundanidad de la existencia permiten comprender a la inteligencia humana que los acontecimientos podrían haber ocurrido de un modo diferente y mejor a como ocurrieron y que la distribución de las cosas podría también ser corregida y mejorada" (Morandé, 1998: 45). Esta apreciación de una lectura de la historia y de la realidad diferente a la existente, justifica la escritura de Isabelle Alonso, siempre orientada a una crítica constructiva de los valores éticos y sociales que rodean al ser humano, ya sea en sus inicios como escritora feminista o actualmente en su vuelco testimonial.

En cuanto a los hermanos, cumplen el papel de primeros amigos, representan las confidencias nocturnas y el intercambio de información sobre los descubrimientos que hacen sobre el mundo: reflexiones sobre los adultos, la escuela o el sexo.

En otra línea, dentro de la familia Alcalá, los nombres de los personajes son marcadamente simbólicos, aspecto común en muchas obras literarias pues "on sait que le nom a toujours fasciné le littérateur; il y voit un signe qui donne aux personnes ou aux lieux une coloration psychique, une résonance singulière, induit les destinées ou révèle les attributs dominants d'un paysage" (Zonabend, 1980: 7).

El nombre de Libertad y de su hermana Harmonia son una representación perfecta de sus personalidades. Libertad, nombre peligroso en la España franquista, procede de una familia burguesa, pero escogerá seguir a su marido Ángel, defensor 
de un mundo justo y libre. A sus ojos, su marido es el ideal no sólo de hombre sino, más ampliamente, de persona que ella busca en su vida:

Lui si différent de tous les autres, lui dont elle était fière, un homme droit, courageux, qui n'avait jamais baissé les yeux. Un homme de conviction, à cent coudées au-dessus du lot des mesquins, dénué de bassesse et de vulgarité. Avec lui, pour lui, elle ferait de grandes choses (Alonso, 2006: 39).

Además, como se ha visto en la descripción de su personaje, es el retrato de una mujer indomable que lucha por sus ideas oponiéndose de las formas más astutas y valientes a cualquier barrera y coacción.

En cuanto a su tía Harmonia, de pequeña es diagnosticada con un soplo en el corazón y, por ello, decide vivir su vida con la máxima calma y serenidad posible. En la novela se rememora como, durante los bombardeos de Madrid, mientras todas las personas corren aterrorizadas intentando ponerse a salvo, ella mantiene su tranquilidad característica sin inmutarse lo más mínimo pues, al fin y al cabo, nadie puede prever donde caerán las bombas por lo que correr de un lado a otro es un trabajo vano. Su filosofía consiste en vivir los buenos momentos y olvidar los malos, “n’en faire qu'à sa tête. Et opposer à ceux qui aimeraient vous en empêcher une force d'inertie inébranlable et silencieuse" (2006: 38). Por otro lado, es el primer miembro de la familia en poder cruzar la frontera con un pasaporte completamente legal, el cual ofrece como regalo a Angustias pues es gracias a ella que lo consigue.

La onomástica forma parte de un juego entre Harmonia y los hermanos Alcalá, el cual pone de relieve, además, la presencia de dos lenguas de las que se desprenden dos visiones del mundo muy distintas. Los Alcalá se divierten traduciendo los nombres femeninos españoles al francés:

À partir de là, ça devenait un jeu dont on ne se laissait pas. Il s'agissait de traduire, pour en souligner le grotesque. À force, on connaissait les mots. Pas forcément leur sens.

- Nuestra Señora de la Purificación?

- Purification!

- De la Consolation comme votre grand-mère paternelle ?

- Consolation!

- Virtudes, comme votre grand-mère, maternelle ?

- Vertus!

- Milagros?

- Miracles!

- Lourdes?

- Apparition dans une grotte!

- Pas exactement, mais à peu près ... Nuestra Señora del Rosario ?

- Rosaire!

- Plus difficile: Pilar?

- Bénitier!

- Amparo?

- Abri!

- Bravo ! Et maintenant, Mercedes? 
- Belle voiture ?

Celle-là, on en redemandait.

- Nooon, ça veut dire grâces, même famille que gracieuse ! Et Dolores, avec ses diminutifs Lola et Lolita?

- Douleurs, Petite-Douleur et Même-pas-mal !

- Ay, ay, ay ! Et Conception, et ses diminutifs Concha et Conchita?

- Idée, Petite-Idée et Toute-petite-idée ! (2006: 42-43).

Este juego onomástico aporta una visión clara del papel dominante que posee la religión católica en España en ese momento, el cual, además, se ve acrecentado durante el franquismo.

Finalmente, en lo que se refiere al nombre de la protagonista, como indica el Diccionario de Nombres de Personas (1993) de Albaigés, Angustias tiene su origen en la palabra latina angustus y significa aquello que es estrecho o angosto y de la palabra ango que significa aquello que oprime. Por lo tanto, significa "aquella que sufre dolor". Su origen se relaciona igualmente con la religión católica. La virgen de las Angustias suele ser representada de pie ante la cruz sosteniendo la corona de espinas de Jesucristo o, en otras ocasiones, sostiene a Jesús sobre su regazo después de su descendimiento. Es igualmente denominada con el nombre de Virgen de los Dolores. En su etimología y simbolismo religioso está claramente asociada a la figura del sufrimiento y del padecimiento.

Tamarit explica que "el nombre no se corresponde con la actitud de la protagonista: fuerte e inteligente, no se dejará arrastrar por la amargura, sino que muy al contrario, se crecerá ante las adversidades" (2007: 151) y, efectivamente, no se relaciona con su forma de ser sino con su elección de aquellos a quienes proteger. Angustias se erige en una heroína que sufre y lucha por todos los oprimidos, por todos los vencidos del mundo. A causa de su situación personal y de la historia de su familia, Angustias siente que debe aportar su grano de arena en la lucha por unos ideales y valores muy concretos que los definen. A lo largo de la novela, protagoniza varios episodios de defensa de sus compañeros de la escuela ante situaciones de desigualdad. Experimenta una gran empatía por los débiles, a los cuales defiende en todo momento y sufre por la existencia de un sistema que divide siempre a las personas en ganadores o perdedores:

Je détestais perdre et n'aimais pas gagner. Que le monde se divise en gagnants et perdants me faisait mal. J'avais pour les gagnants, leur morgue, leur efficacité et leur sourire triomphant une antipathie spontanée qui m'empêchait de savourer mes propres victoires. J'avais pour les perdants une empathie immédiate, profonde, j'étais de leur côté. Je ne pouvais m'identifier qu'à eux. N'étions-nous pas, nous, les Alcalá, les grands comme les enfants, ceux d'ici comme ceux de là-bas, toute une famille de perdants? Et n'étions-nous pas de perdants justement parce que nous n'avions jamais accepté de passer du côté de plus forts ? Et que nous avions raison? (Alonso, 2006: 202).

A lo largo de este primer punto se ha podido observar de qué manera se inscribe cada miembro en la vida de Angustias. Del análisis se desprende que se trata de una familia muy unida, donde todos aportan elementos imprescindibles para afrontar una situación 
muy difícil, como es la del exilio. El universo creado por Isabelle Alonso se sustenta gracias a un engranaje perfecto. La madre, pilar familiar, posee una gran capacidad de superación para construir lo máximo con lo mínimo. El padre, figura idealista, es el portador de los valores políticos y sociales. Los hermanos, confidentes nocturnos, ayudan a Angustias en la exploración del mundo, junto a ellos se desarrollan las diversas hipótesis que buscan entender cada cambio, cada movimiento de su alrededor.

\section{La herencia del tópico}

El análisis de la imagen o representación que una sociedad tiene del Otro debe tener en cuenta el imaginario social, puesto que cada conciencia humana afirma su singularidad o identidad a partir de sus peculiaridades y diferencias con respecto al resto de personas. Además, puede observarse que esta diferenciación se produce también en comunidades o grupos de personas respecto a otras comunidades. De esta forma, es posible afirmar que cada conciencia humana individual forma parte y se desarrolla a su vez dentro de una conciencia humana colectiva determinada, es decir, la conciencia singular de un individuo es deudora en bastantes rasgos del imaginario social en el que se inscribe. Se utiliza aquí el término "imaginario" en el sentido en que lo emplea Charles Taylor (2006) refiriéndose a la manera en que las personas imaginan su entorno social manifestado a través de imágenes o leyendas y no en términos teóricos. Este imaginario es el que permite un sentimiento de legitimidad compartido por grandes grupos de personas o sociedades.

Este fenómeno no tiene relevancia únicamente en la forma en que la sociedad se concibe a sí misma sino también en la manera en que concibe al Otro, al extranjero. Esta concepción es fruto de la separación de dos órdenes de realidad cultural diferentes, razón por la cual está caracterizada por "una profunda bipolaridad: identidad versus alteridad" (Pageaux, 1994: 103). Las imágenes se forman a partir de la concienciación de un Yo en oposición a un Otro. Si bien no es posible rastrear el origen de todos los mitos y estereotipos que forman parte del imaginario social, sí que es posible encontrar la raíz de algunos de ellos en ciertos sucesos históricos y en la literatura como se mostrará a lo largo de este capítulo.

A lo largo de esta novela, la autora plantea una reflexión bastante crítica sobre los tópicos y estereotipos presentes en la sociedad francesa a los que los diversos personajes de la novela deben enfrentarse. A la luz de un testimonio en el que conviven sujetos de diferentes generaciones de exiliados, el análisis de este factor resulta muy interesante en tanto que plantea la cuestión de la extranjería como un elemento hereditario.

El estudio de la imagen de España en Francia revela como la relación hispanofrancesa se mueve constantemente entre la hispanofobia y la hispanomanía. Marín Ruiz (2009), explica que la unión entre Castilla y Aragón en un proyecto imperial para aumentar y expandir el dominio español despertó los recelos de los poderes europeos; los cuales, para intentar neutralizar el poder económico y militar de Carlos V y Felipe II, encontraron un arma efectiva en la propaganda negativa. Se empezó a transmitir y forjar en Francia y en Inglaterra la conocida como Leyenda Negra:

En una palabra, entendemos por leyenda negra, la leyenda de la España inquisitorial, ignorante, fanática, incapaz de figurar entre los pueblos cultos lo mismo ahora que antes, dispuesta siempre á las represiones violentas; enemiga del progreso y 
de las innovaciones; ó, en otros términos, la leyenda que habiendo empezado á difundirse en el siglo XVI, á raíz de la Reforma, no ha dejado de utilizarse en contra nuestra desde entonces y más especialmente en momentos críticos de nuestra vida nacional (Juderías, 1914: 15).

Como indica Juderías la leyenda negra no tiene repercusiones únicamente en su época de origen, sino que los estereotipos surgidos de esta propaganda acompañan la imagen de España durante un largo período. De hecho, es posible encontrar trazas de ese tópico todavía en la actualidad. En esta novela, aparece representado en la relación de los diferentes países y sus respectivos idiomas. A través de un análisis de las lenguas, la autora explica cómo los diferentes sistemas fonéticos influyen en la visión que las personas tienen de los distintos países. Mientras que las vocales son representadas, para Angustias, como bailarinas alegres cuyas poses se encargan de embellecer y dar música a las palabras, las consonantes son serios soldados con uniformes color kaki, encargados de estructurar y dar solidez y fiabilidad a las palabras. Así, los países ricos y prósperos, los del Norte, están caracterizados por un sistema fonético en el que predominan las consonantes y los países del sur, con sus vocales alegres y fantasiosas, representan una tierra destinada únicamente a las canciones y a las vacaciones. Cuando los franceses miran hacia abajo lo hacen con arrogancia: españoles, portugueses, italianos, árabes, "rastaquouères et compagnie" (Alonso, 2006: 86), en cambio, el norte es visto con "une pointe de jalousie admirative" (Alonso, 2006: 86).

Durante el Romanticismo, los tonos lúgubres hacia España disminuyen y el país se convierte en el destino preferido de los románticos. No obstante, ciertos estereotipos procedentes de épocas anteriores no desaparecen, sino que coexisten con la nueva imagen de la España de principios del siglo XIX. Esta coexistencia de los estereotipos procedentes de la leyenda negra junto a los nuevos propagados por los románticos darán lugar al nacimiento del tópico de "la España de pandereta, es decir, la representación del país como un lugar caracterizado por el atraso material, el orgullo, el honor, el folklore, la crueldad, la devoción o la pereza, entre otros rasgos" (Marín, 2009: 7).

La definición de los españoles que aparece en el Dictionnaire portatif de géographie universelle de Boiste (1806) es un documento que expone claramente la bipolar visión que los franceses tienen de los españoles:

Les Espagnols sont grands, ont le teint brun, sont orgueilleux, loyaux et humains, paresseux et sobres, patients et spirituels, très galants, moins jaloux qu'autrefois ; les femmes sont d'une taille petite et svelte, ont beaucoup d'esprit et de vivacité : la langue espagnole, dialecte du latin mêlé d'arabe, est sonore. Majestueuse et sublime, mais pauvre (1806: 327).

Como se puede observar en esta definición, los adjetivos que se utilizan para caracterizar a los españoles van de lo negativo a lo positivo indistintamente y en ocasiones, incluso, se contradicen.

Por otro lado, cabe tener en cuenta la gran influencia que ejerce la literatura en esta época por lo que la visión del Otro no sólo es relevante desde un punto de vista literario, sino que tiene influencia en la sociedad, es un transmisor de estereotipos: "ainsi 
conçue, l'image littéraire est un ensemble d'idées et de sentiments sur l'étranger prises dans un processus de littérarisation mais aussi de socialisation" (Pageaux, 1994: 140). En este ámbito, algunos autores encuentran en España un ideal de exotismo como es el caso de Prosper Mérimée o Théophile Gautier mientras que otros escritores como Stendhal mantienen la visión de una España anclada en la antigüedad, obsoleta, despótica y cruel. En cualquier caso, a pesar de la visión negativa de algunos autores, lo cierto es que la visión idealizada de España será la que más calado tenga en la sociedad francesa. Esta idealización y exageración de los estereotipos españoles contribuye a la propagación del ya citado tópico de la España de pandereta, que entra a formar parte del imaginario social francés y sigue perdurando actualmente. Ejemplo de ello es la escena del padre de Angustias haciendo frente a esta visión:

Des blagues de ses compagnons de circonstance. Angel en avait entendu d'autres à l'armée, mais ce genre d'humour ne le faisait tout simplement pas rire, pas sourire même. Quand ils le questionnaient sur sa vie, Angel se vengeait. Comment elle est ta femme? Elle est belle, très belle. Elle danse le flamenco ? Bien sûr que oui. Tous les matins elle met ses castagnettes, sa robe à pois, et elle se lance dans des pirouettes et des zapateados jusqu'à l'heure du repas. Et t'as déjà vu une corrida? Non seulement j'ai vu une corrida, mais on a un taureau à la maison, qui s'appelle Paquito, et tous les soirs faut le sortir pisser, une creaie corvée. Tu te foutrais pas un peu de nous? Pas mon genre. T'as qu'à nous faire la voir ta femme, t'as bien une photo ? Bien sûr que j'ai une photo, mais je ne vous la montrerai jamais, nous les Espagnols on est très jaloux. Si tu voyais ma femme, je serais obligé de te tuer, c'est comme ça, c'est la coutume (2006: 27).

Estos tópicos a los que recurren los compañeros de trabajo de Ángel para intentar bromear con él, muestran como en pleno siglo XX todavía se mantiene la visión heredada de la leyenda negra y de la España de pandereta. Como ya señalaba Juderías, "querámoslo ó no, los españoles tenemos que ser, individual y colectivamente, crueles é intolerantes, amigos de espectáculos bárbaros y enemigos de toda manifestación de cultura y de progreso" (Juderías, 1914: 6).

Por consiguiente, cabe concluir que la presencia de tópicos y estereotipos en el imaginario colectivo tiene una gran repercusión en la vida de los exiliados, pero, además, como se ha señalado anteriormente, en esta novela conviven diferentes generaciones, con lo cual conviene ahora indagar sobre las consecuencias que sufren los hijos de los exiliados nacidos en Francia. En este contexto, L'Exil est mon pays emite una sentencia muy firme y definitoria de la situación: "comme tous les réfugiés, je ne suis pas d'ici, je ne suis pas du pays où je suis née” (2006: 19).

En una sola oración la autora consigue transmitir la gran problemática que viven los hijos de exiliados e inmigrantes, es decir, la mal denominada "segunda generación". Dicho término induce a pensar que se trata de una segunda remesa de inmigrantes y refugiados, pero, lo cierto es que las diferencias entre una generación y otra son abismales. No obstante, como afirma la protagonista de la novela "nous, leurs enfants, sommes nés étrangers. Car l'étrangeté, c'est héréditaire” (2006: 64).

Esta generación experimenta grandes distancias con la generación anterior, pero, también, con su propia generación en el lugar de acogida. Esto comporta que el sujeto no consiga inscribirse geográficamente en ningún espacio, se siente desprotegido en 
todo momento; posee, por una parte, unos orígenes y, por otra, una tierra en la que se desarrolla y que también siente como propia pero las circunstancias no le permiten enraizarse en ninguno de los dos. Por consiguiente, su identidad también se encuentra desplazada, insegura por la imposibilidad de inscripción: "los hijos de inmigrantes parecen condenados a ubicarse en un "entre dos", entre dos países, dos culturas, dos idiomas, incluso, a veces, entre dos religiones" (Hadj, 2008: 37). Como indica Hadj la consecuencia principal es la invisibilización y la ignorancia de sus peculiaridades a causa de la dificultad de inscribirlos en un sector definido de la sociedad. El acto de migrar lleva siempre implícita una alteración de la identidad de alguna manera, pero, en este caso, "la identidad está en constante proceso de construcción, es un puzzle cuyas piezas no siempre encajan, ni son coherentes, pero que responden a una necesidad visceral de reconocimiento cualquiera que sea su procedencia" (2008: 37).

Hadj se apoya en los estudios de Emmanuelle Santelli (2001) quien explica que referirse a esta generación como inmigrantes o extranjeros cuando han nacido en el país, provoca una ilusión falsa en el imaginario colectivo, hace pensar que están ante recién llegados. Sin embargo, han nacido, se han educado, han socializado y, en definitiva, han hecho sus vidas en este país. La continuación de esta idea en la sociedad respalda la afirmación de la protagonista de la novela cuando afirma que la extranjería es algo hereditario:

La propia denominación que se les otorga, segunda generación de inmigrantes, ya indica que el elemento que rige a la hora de su identificación consiste, fundamentalmente, en su extranjería. Una extranjería que, curiosamente, se hereda. Los inmigrantes nunca dejan de ser extranjeros y los hijos de estos deben convivir, a su vez, con este estigma (Hadj, 2008: 38).

La autora aprovecha para lanzar una crítica a la situación actual de la extranjería. Señala que mientras antes los extranjeros eran considerados como individuos, como personas, actualmente han sido reducidos a meras estadísticas, a una simple cantidad en un papel, “à un magma indifférencié propice aux frayeurs des autochtones, enracinés depuis des générations, tremblant pour leurs pantoufles à la vue de ces crèvela-faim à qui la misère met le feu aux espadrilles" (Alonso, 2006: 61). No obstante, pone en evidencia que tanto antes como ahora conviene no olvidar que no todas esas personas se exilian o emigran a causa de la pobreza, sino que las guerras y la falta de derechos, entre otras, siguen siendo causas actuales en el siglo XXI.

Como se ha comprobado a lo largo de este apartado, el testimonio literario de Isabelle Alonso plasma con suma perfección, por un lado, la presencia de un imaginario social profundamente anclado en la sociedad, al que los personajes deben enfrentarse en su día a día, independientemente de su país de origen, revelando la limitada comprensión existente acerca las peculiaridades de cada generación, así como sobre la realidad del país vecino.

\section{Vivir entre dos lenguas}

Plantearse abordar cómo se desarrolla la cuestión lingüística en los hijos de los exiliados, conlleva irremediablemente interrogarse a propósito del factor identitario. En 
los casos en los que el sujeto posee más de una lengua y más de una cultura, suele experimentar problemas para conseguir situarse en un espacio definido. Por esta razón, los testimonios aportados por los autores se presentan como un viaje exploratorio, donde el exiliado intenta adentrarse en cada rincón, en cada pilar que sustenta la dualidad de su vida. Se trata de un viaje que se inicia con muchas preguntas identitarias y pretende volver a recorrer, reconstruyendo, analizando y pidiendo la ayuda del lector para llegar a una posible respuesta, a una posible conjugación de las culturas. Esta búsqueda de la propia identidad es una característica común de los exiliados españoles en Francia pues como explica Molina, "ressentent un besoin pressant de revenir sur leurs origines, non seulement personnelles mais aussi historiques" (2007: 122).

En la novela de Isabelle Alonso, se pone de relieve la experiencia de la lengua no como simple vehículo de comunicación sino como elemento definitorio de la identidad, la cual se halla desdoblada a causa de la presencia de dos lenguas, como se expondrá a continuación.

Para la protagonista ser bilingüe supone tener dos mundos diferentes y hace una diferenciación entre la lengua española, representativa del núcleo familiar, y la lengua francesa, considerada como la lengua "del exterior". La lengua francesa es un idioma que todavía no domina totalmente. Sirve para la vida social, con ella se relaciona con los compañeros de clase, profesores, con todos aquellos que no pertenecen a su núcleo familiar. Esta lengua se inscribe en su conciencia como una herramienta de trabajo para afrontar las dificultades del día a día: "une langue un peu sèche, presque hostile, comme une arme pour se défendre" (Alonso, 2006: 75). La lengua española, al contrario, es una lengua familiar donde se alberga la seguridad, la protección; en ella la protagonista se siente en su elemento. En el idioma español, se encuentra, por una parte, el universo de la ternura representado por la figura materna:

Mots de Libertad, qui nous racontait des histoires pour nous faire manger, nous fredonnait des chansons pour nous endormir, nous donnait des petits noms qui fondaient dans l'oreille comme des bonbons, faisaient mercurochrome sur le chagrin cielo, cariño, corazón, chiquitita (2006: 75-76).

Como indican Di Meo, Sanson, Simon et al. (2014) la lengua materna tiene un papel muy importante en las interacciones entre la madre y el niño. De forma universal, la melodía y los contornos de la voz materna se despliegan preferentemente en su lengua originaria suscitando y provocando placer en el bebé. Por consiguiente, desde el primer momento el niño está creando un vínculo muy fuerte con su madre gracias a un código común. En este sentido, es natural que la lengua materna sea asociada al universo del amor y la ternura.

Por otro lado, en la lengua española se encuentra también el universo del humor, representado por la figura paterna. Ángel acostumbra a bautizar a sus hijos con nombres divertidos para desencadenar la risa en la familia. Cada hermano Alcalá posee dos nombres, el oficial y el humorístico inventado por su padre: Angustias es Gutapercha, Remedios es Micomicona como la princesa de Don Quijote, Gonzalo se convierte en Pangorcio y Rodrigo en Pocotilo.

La existencia de dos nombres juega un gran papel en la presencia de dos espacios muy diferenciados a través de las lenguas. El exterior, espacio serio que encarar con un escudo protector, se afronta con el nombre oficial; en cambio, el interior está ca- 
racterizado por un sentimiento de tranquilidad y comodidad total que abre la puerta a la comicidad.

En otra línea, es indispensable entender la importancia del papel que juega la territorialidad en la formación identitaria de sujetos y comunidades. Los procesos de territorialidad producen manifestaciones a diversas escalas y esto conlleva que la localización dentro de un territorio concreto determine la membresía, el sentimiento de pertenencia a un grupo. Dentro de lo cual, explica Sánchez Ayala (2015), estar dentro o fuera de ese territorio es uno de los factores de mayor significado. Cuando un sujeto se siente territorialmente dentro, ese sentimiento se enlaza con el de seguridad, se siente, al mismo tiempo, fuera de peligro, protegido de cualquier tipo de amenaza. Sentirse fuera del territorio, al contrario, conlleva que el individuo se sienta alejado y separado y empiece a desarrollar una especie de separación, experimenta una división entre él y el resto del mundo. Por consiguiente, cuanto más profundamente se inserta la persona en el interior de un territorio, más fuerte es igualmente su identidad con dicho lugar:

Fenomenológicamente, el punto crucial es que estar dentro o fuera constituye una dialéctica fundamental en la vida humana y que, a través de diversas combinaciones e intensidades de estar dentro o fuera, diferentes lugares sumen distintas identidades para diferentes individuos y grupos, y la experiencia humana adquiere disímiles cualidades en cuanto a emociones, significados, relación con el entorno, y acción. Esto apunta a que nuestras organizaciones territoriales puedan significar y crear percepciones que den la sensación de que el mundo esté cerrado o abierto para nosotros (Sánchez Ayala, 2015: 176).

De estas palabras se desprende que un proceso de territorialización tiene un alcance mayor que el de simple estrategia de control espacial. Lo cierto es que posee una implicación en la forma de pensar y actuar e, igualmente, en las cosmovisiones que se cimientan sobre las creencias y formas de conocer cultural e históricamente contingentes. De esta forma, el territorio se convierte en una suerte de instrumento comunicativo que muestra las estructuras sociales, entre ellas, la identidad, los derechos, los prejuicios, entre otras. Por otro lado, cabe incorporar a esta teoría las implicaciones y modificaciones que pueden producirse a causa del factor lingüístico. La escisión traumática en el sujeto, consecuencia del sentimiento de estar fuera del territorio, se acrecienta a causa de las variables aportadas por las lenguas. Los idiomas son, como se ha indicado, productores de espacios diferenciados por los sentimientos, recuerdos e ideas que vehiculan cada uno de ellos. De tal modo que, dentro de un mismo territorio, la lengua crea dos espacios diferentes, dentro de los cuales, el sujeto se sentirá dentro o fuera de ellos según su dominio del código lingüístico que comparten y que caracteriza a los miembros que se incluyen dentro de ellos. Estos dos espacios, bordeados a través del lenguaje, son relevantes no sólo en el proceso de formación identitario del sujeto sino en el mismo quehacer diario, pues materializan lingüísticamente el sentimiento de pertenencia, así como el de exclusión. El desconocimiento del código común conlleva el sentimiento de estar fuera de lugar.

L'Exil est mon pays está contado desde la perspectiva de una niña pequeña y no desde la perspectiva de un adulto que evoca su infancia, por esta razón, en esta novela la conciencia de poseer dos lenguas debido al hecho de ser extranjeros no es 
clara en la mente de Angustias. Esto se revela cuando la protagonista es invitada a merendar en casa de su amiga Marine. La protagonista siente una gran contrariedad porque ella observa que la madre de su amiga utiliza la lengua del exterior, el francés, dentro de su casa. Angustias siente este hecho como una muestra de odio, de desprecio hacia los niños y, es a partir de la vivencia de este episodio, que el lector comprende como el bilingüismo se desarrolla en el mundo de Angustias, en sus dos mundos. Ella no lo concibe como algo único en su familia, como un fenómeno en estrecha relación con su condición de extranjera, sino como algo universal. Su madre le explica que "rien de grave, ça veut dire qu'on est espagnols, qu'on n'est pas d'ici, on vient d'un autre pays, et donc, on parle espagnol" (2006: 79). Este suceso no sólo le sirve para descubrir su condición de extranjera, sino que, además, puede poner fin a su búsqueda de aquello que la diferencia de los demás: "être étranger, finalement, ce n'était pas avoir quelque chose en moins, mais quelque chose en plus. Les Français n'étaient jamais que des gens qui parlaient qu'une langue” (2006: 80).

Cuando Angustias viaja a España, piensa que por fin va a estar en su tierra, en un lugar donde ya no se la considerará como diferente. Tamarit (2010) explica como para los inmigrantes de la segunda generación el retorno al país de acogida tiene una peculiaridad diferente con respecto a sus padres, si bien no es la respuesta a su búsqueda identitaria permanece en el imaginario como un lugar idealizado, posible escape ante una sociedad en la que nacieron pero que, a veces, se les presenta hostil. En el caso de Alonso, este imaginario se rompe al sentir su diferencia en España pues descubre que su pronunciación de las $\mathrm{R}$ y las $\mathrm{Z}$ y algunas expresiones o frases la hacen pasar por francesa. En ese momento, el desorden de la protagonista alcanza su punto más álgido y desconcertante: si es una extranjera española en Francia, también es una extranjera francesa en España.

Finalmente, la protagonista acepta que su vida tendrá lugar siempre entre dos mundos diferentes. Su identidad será siempre doble, híbrida, multicultural:

Apatrides, cosmopolites, persécutés, expulsés, arrachés, déracinés, émigrés, réfugiés, transplantés, greffés, rejetés, assimilés, intégrés, disparus... Je marche aux côtés de tous les vaincus de la terre, chassés par les caïns éternels sur les routes sans fin de la défaite. Ces routes, je n'y ai jamais mis les pieds et quiconque m'observerait, déambulant dans une rue parisienne, humant l'air du temps, guettant d'un œil expert les nouveautés des boutiques, en verrait qu'une bourgeoise en goguette et un exemple encourageant d'intégration réussie. Les escadrons de l'exil qui campent la nuit de mon esprit ne sont pas visibles à l'œil un. J'ai passé des années à les cacher pour faire semblant d'être comme tout le monde. Mais moi je suis du pays des étrangers, des exilés. Les miens. L'exil est mon pays (Alonso, 2006: 297).

Se identifica con todos los exiliados de la historia, con todos aquellos que tienen la convicción íntima de ser diferentes, pero también de poseer algo más que los otros.

\section{Conclusión}

En esta obra, la escritora Isabelle Alonso se vale de la creación de la figura de Angustias, su alter ego, para poder iniciar en máxima libertad el testimonio de su búsqueda 
identitaria. En su escritura, los elementos identitarios claves son la familia, la presencia de prejuicios históricos en el país de acogida, al cual, por otro lado, pertenece de pleno derecho y, finalmente, la presencia de dos lenguas y dos culturas que deben encontrar la manera de coexistir.

Esta coexistencia cultural y lingüística podría darse plácidamente tal como señala la tesis que Glissant aplica a la literatura, siguiendo las teorías de Deleuze \& Guattari (2004) a propósito de la identidad-rizoma. Las organizaciones disciplinares jerárquicas limitan las posibilidades de aprehender la realidad, de percibir cada nuevo matiz y cada diferencia dentro del grupo. Al igual que "cualquier punto de un rizoma puede ser conectado con cualquier otro y debe estarlo" (Deleuze \& Guattari, 2004: 13) convirtiéndose en un elemento muy diferente de su origen y creando una rica heterogeneidad; Glissant lo extrapola a la identidad de los pueblos para hablar de su pluralidad. Los pueblos tienen su origen en un tallo único que ha ido evolucionando a lo largo de la historia, gracias a la continua conexión de sus raíces. En esta línea, el rizoma es esa interconexión que da lugar a una identidad caracterizada por su multiplicidad. Esta identidad-rizoma está en movimiento perpetuo, al contrario de la identidad-raíz, estática y rígida, defendida por los nacionalismos. Se trata de un concepto de identidad que contempla la diversidad existente en el alma de todo pueblo, de toda cultura. Abre una nueva vía para la aceptación de las diferencias, no como algo negativo sino como algo enriquecedor. Es esta noción de identidad-rizoma la que podría conseguir que la protagonista de L'Exil est mon pays (2006) no se sienta desplazada, en tierra de nadie, a causa de sus diferencias con el resto de compañeros. Como señala Glissant "las opacidades pueden coexistir, confluir, tramando tejidos de forma tal que la verdadera comprensión portará sobre la textura de esta trama y no sobre la naturaleza de los componentes" (1990: 204). Esto se produce al que igual que el arte, las identidades y las culturas están en incesante movimiento de creación, de sinergia. Es esta lucha por la aceptación de la diversidad, de la multiplicidad de componentes que pueden dar vida a un ser, la que confiere el valor a estos testimonios del exilio, de la búsqueda del paso de la identidad raíz a la identidad rizoma.

En otro orden de ideas, cabe señalar que el hecho de que la escritura no se restrinja a la historia de Angustias, sino que se trate de una novela que profundiza en mayor o menor grado en todos los miembros de la familia, ofrece una perspectiva mucho más amplia y enriquecedora pues permite observar las grandes diferencias existentes entre las dos generaciones de exiliados.

Aruj \& González (2007) señalan que en el momento en que se abandona el país de origen se produce el sentimiento de desarraigo. Se trata de "la situación de ambivalencia que implica el vivir al mismo tiempo entre dos espacios: el de origen y el de exilio, a la espera del retorno, sin certeza" (2007: 29). En el caso de Angustias, exiliada de la segunda generación, al haber nacido en Francia y ser, por tanto, extranjera por herencia, se observa que el espacio de origen y el del exilio coinciden, lo que supone una gran diferencia con la primera generación. Sin embargo, es posible comprobar que los sentimientos germinados coinciden en ambas pues experimentan "una constante recreación de esta situación de 'extrañeza y ajenidad', de no pertenecer al lugar donde se vive, y de pertenecer a otro donde no se puede vivir" (2007: 29).

En otra línea, se ha visto que los problemas y las inquietudes de los padres están relacionados con la economía y la política, con el hecho de haber dejado atrás una vida y un país, con lo cual, el mito del retorno siempre está presente en su imaginario, en su día a día. No obstante, no se observa ningún problema identitario en ellos, 
a salvedad del conflicto moral que les provoca la aceptación de la nacionalidad. En cambio, los hijos viven sumidos en una búsqueda identitaria obsesiva que, en ocasiones, nunca podrán concluir:

Ahí reside la diferencia principal entre la generación que emprende la inmigración
y la de sus descendientes; los primeros no tienen duda en cuanto a sus orígenes,
tienen identificadas sus raíces, su historia, su idioma, sus creencias; sin embargo,
los hijos de estos inmigrantes no saben dónde ubicarse, se debaten entre la necesi-
dad de seguir una línea marcada por la historia familiar y la urgencia de entrar en
el molde de la sociedad en la que han nacido (Hadj, 2008: 38).

Como se observa en el caso de Angustias, para ella el mundo se presenta desdoblado pues existen siempre dos formas de ver las cosas y su vida se divide en dos espacios delimitados por el idioma y las personas que lo componen:

Il y avait toujours, toujours deux manières de voir les choses. Depuis la famille, ou depuis l'école. À la française, ou à l'espagnole. Ce qui se passait à l'intérieur de moi, ou ce que j'en laissais voir à l'extérieur. On pouvait à la fois gagner et perdre, être heureux ou malheureux. Ça dépendait seulement du point de vue qu'on choisissait. Et moi j'aurais voulu ne jamais avoir à choisir (Alonso, 2006: 202).

La presencia de dos espacios que conforman su vida y a los que ella pertenece provocan que no sea capaz de sentirse en ninguno de ellos plenamente y, como consecuencia, explica que "je commençais, sans le savoir, à cultiver le complexe du clandestin, celui de tous ceux qui prennent conscience un jour qu'ils sont nés au mauvais endroit ou au mauvais moment, avec la gueule ou avec le cul qu'il en faut pas" (2006: 65). La doble pertenencia, paradójicamente, le niega un territorio en el que poder inscribirse sin perder o traicionar alguna parte de su ser. Debe situarse entonces en el espacio de la no pertenencia, pues parece imposible evitar la situación exiliar y así explica Bolzman que:

Les jeunes de la deuxième génération ont vécu toute ou une grande partie de leur vie dans un pays qui n'est pas formellement le leur, mais qu'ils connaissent mieux que celui censé être le leur. En ce sens on peut affirmer qu'ils sont à la fois des enfants de deux sociétés et des enfants de nulle part. Leur véritable patrie est l'exil (1996: 231).

En este contexto, cabe mencionar la obra Psychologie des Exils (1977) de Hilde Spiel, donde explica que la transformación de la conciencia del emigrante en una esquizofrenia mental a causa de la presencia de varias lenguas, es un elemento más negativo que la privación física o las preocupaciones materiales. La escisión latente en estos sujetos corre el peligro de volverse patológica, peligrosa si no se llega a una integración de las culturas. En este marco, la literatura intercultural, conocida como "littérature de l'entre-deux" abre infinitas posibilidades de expresión artística que pueden lidiar con esa problemática y transformarla en una obra de arte que sobrepase la inmediatez espacio-temporal. En esta línea, Isabelle Alonso ha sabido expresar y 
plasmar en su obra, esa invención de nuevos territorios y espacios de inscripción a los que alude Nuselovici (2013). En este país en el que se integran todos los desterrados de la historia, el exilio deja de ser entendido como un límite que marca la división y la diferenciación entre dos territorios, dos culturas, dos lenguas, en suma, entre dos concepciones excluyentes del mundo.

\section{Referencias bibliográficas}

Albaigués, J. M., (1963) Diccionario de nombres de personas. Barcelona, Publicaciones de la Universidad de Barcelona.

Alonso, I., (2006) L'Exil est mon pays. París, Héloïse d'Ormesson.

Alonso, I., (2016) Je mourrai une autre fois. París, Héloïse d'Ormesson.

Aruj, R. \& E. González, (2007) El retorno de los hijos del exilio. Una nueva comunidad de inmigrantes. Buenos Aires, Prometeo libros.

Boiste, P. C., (1806) Dictionnaire portatif de géographie universelle. París, Chez Desray.

Bolzman, C., (2012) "Elementos para una aproximación teórica al exilio" in Revista andaluza de antropología. $\mathrm{N}^{\circ} 3$, Migraciones en la globalización, pp.7-30.

Deleuze, G. \& F. Guattari, (2004) Mil mesetas. Capitalismo y esquizofrenia. Valencia, PreTextos.

Glissant, É., (1990) Poétique de la Relation. Poétique III. París, Gallimard.

Hadj Handri, N., (2008) "La identidad mutante. La construcción de la identidad en los hijos de inmigrantes" in Revista de documentación social. No151, Cáritas, pp. 35-48.

Juderías, J., (1914) La leyenda negra y la verdad histórica. Madrid, Revista de Archivos.

Marín Ruíz, R., (2009) Tres visiones de España durante la guerra civil. España, Nausícaä.

Molina Romero, C., (2007) "Écrivains afrancesados au XX' siècle" in Gasquet, A. \& M. Suárez (dir.), Écrivains multilingues et écritures métisses. L'hospitalité des langues. Clermont-Ferrand, Presses Universitaires Blaise Pascal.

Morandé, P., (1998) Familia y sociedad. Reflexiones sociológicas. Santiago de Chile, Editorial Universitaria.

Nuselovici, A., (2013) "Exiliance: condition et conscience" in FMSH. No44, pp. 1-12.

Pageaux, D. H., (1995) "Recherche sur l'imagologie: de l'histoire culturelle à la poétique" in Thélème: Revista complutense de estudios franceses. $\mathrm{N}^{\circ} 8$, pp.135-160.

Santelli, E., (2001) La mobilité sociale dans l'immigration. Itinéraires de réussite des enfants d'origine algérienne. Toulouse, Presse universitaire du Mirail.

Spiel, H., (1975) "Psychologie des Exils" in Neue Rundschau. No86, pp. 424-439.

Tamarit, I., (2007) "La búsqueda de la propia identidad en L'exil est mon pays de Isabelle Alonso" in Quaderns de filologia. Estudis literaris. $\mathrm{N}^{\mathrm{o}} 12$, pp. 147-158.

Taylor, C., (2006) Imaginarios sociales modernos. Barcelona, Paidós.

Todorov, T., (1989) Nous et les autres. La réflexion française sur la diversité humaine. París, Seuil.

Zonabend, F., (1980) "Le nom de personne" in L'Homme. Révue française d'anthropologie. Vol. 20, nº 4 , pp.7-23. 